\title{
An alternative method for correcting fluorescence quenching
}

\author{
L. Biermann ${ }^{1}$, C. Guinet $^{2}$, M. Bester ${ }^{3}$, A. Brierley ${ }^{4}$, and L. Boehme ${ }^{1}$ \\ ${ }^{1}$ Sea Mammal Research Unit, Scottish Oceans Institute, St. Andrews, UK \\ ${ }^{2}$ Centre National de la Recherche Scientifique, Centre d'Etudes Biologiques de Chizé, Villiers en Bois, France \\ ${ }^{3}$ Mammal Research Institute, Department of Zoology and Entomology, University of Pretoria, Pretoria, South Africa \\ ${ }^{4}$ Pelagic Ecology Research Group, Scottish Oceans Institute, St. Andrews, UK
}

Correspondence to: L. Biermann (lb66@st-andrews.ac.uk)

Received: 8 April 2014 - Published in Ocean Sci. Discuss.: 9 May 2014

Revised: 8 December 2014 - Accepted: 11 December 2014 - Published: 13 January 2015

\begin{abstract}
Under high light intensity, phytoplankton protect their photosystems from bleaching through nonphotochemical quenching processes. The consequence of this is suppression of fluorescence emission, which must be corrected when measuring in situ yield with fluorometers. We present data from the Southern Ocean, collected over five austral summers by 19 southern elephant seals tagged with fluorometers. Conventionally, fluorescence data collected during the day (quenched) were corrected using the limit of the mixed layer, assuming that phytoplankton are uniformly mixed from the surface to this depth. However, distinct deep fluorescence maxima were measured in approximately $30 \%$ of the night (unquenched) data. To account for the evidence that chlorophyll is not uniformly mixed in the upper layer, we propose correcting from the limit of the euphotic zone, defined as the depth at which photosynthetically available radiation is $\sim 1 \%$ of the surface value. Mixed layer depth exceeded euphotic depth over $80 \%$ of the time. Under these conditions, quenching was corrected from the depth of the remotely derived euphotic zone $Z_{\mathrm{eu}}$, and compared with fluorescence corrected from the depth of the density-derived mixed layer. Deep fluorescence maxima were evident in only $10 \%$ of the day data when correcting from mixed layer depth. This was doubled to $21 \%$ when correcting from $Z_{\mathrm{eu}}$, more closely matching the unquenched (night) data. Furthermore, correcting from $Z_{\text {eu }}$ served to conserve non-uniform chlorophyll features found between the $1 \%$ light level and mixed layer depth.
\end{abstract}

\section{Introduction}

Monitoring distribution and abundance of primary producers in the marine environment is useful for understanding larger biological and physical processes. Phytoplankton are predominantly single-celled, green microscopic organisms, present at variable concentrations in every ocean (Falkowski and Kolber, 1995; Behrenfeld et al., 2009). They are the first stepping stone in transferring energy into the marine ecosystem. When conditions allow for growth, their collective impact is such that they are able to change the spectral properties of the water (McClain, 2009). This can be exploited to measure abundance and distribution using their photosynthetic pigment, chlorophyll $a(\mathrm{Chl} a)$ as a marker (Morel and Prieur, 1977; Gordon and Morel, 1983; Falkowski et al., 1998; Henson et al., 2010).

Satellite-derived ocean colour is the most comprehensive data set available for monitoring surface $\mathrm{Chl} a$ concentration. However, the limitations of remote sensing are significant (Dierssen and Smith, 2000; McClain, 2009). Perhaps most significantly, satellite sensors can only see ocean colour from the surface to one optical depth, providing little information on the vertical structure of the water column (Morel and Berthon, 1989). Despite innovative algorithms to improve data collected by satellites, limitations are not likely to be resolved with the next generation of ocean colour sensors. Continued collection of in situ data on phytoplankton distribution and abundance is thus essential (Johnson et al., 2009).

Fluorescence has been widely used as a relatively inexpensive, non-invasive method for quantifying $\mathrm{Chl} a$ since the 1960s (Lorenzen, 1966; Lorenzen and Jeffrey, 1980; Cullen 
and Eppley, 1981; Falkowski and Kolber, 1995; Xing et al., 2011; Lavigne et al., 2012). Chlorophyll pigments packaged inside phytoplankton cells re-radiate $\sim 2 \%$ of light energy as fluorescence. Active fluorescence can thus be measured by a fluorometer delivering voltage output equivalent to $460 \mathrm{~nm}$ (excitation in the blue) and measuring resultant fluorescence in the $620-715 \mathrm{~nm}$ range (detection in the red). Assuming that the measured yield is proportional to the abundance of photosynthesising phytoplankton, relative values of fluorescence can be used to quantify primary biomass. However, yield (and thus proportionality) is affected by several factors, including the intensity of sunlight each cell is exposed to (Behrenfeld and Boss, 2006).

To regulate high sunlight intensity, phytoplankton employ the mechanism of non-photochemical quenching. This process helps cells protect themselves in environments where light energy absorption exceeds the capacity for light utilisation (Müller et al., 2001; Behrenfeld et al., 2009). During periods of high light stress, shallow-mixed phytoplankton in the upper euphotic zone protect their photosystems from bleaching by emitting excess energy as heat (Milligan et al., 2012). In this state of photo-protection, photosynthesis is inhibited and fluorescence yield drops (Müller et al., 2001). However, deep-mixed phytoplankton are shaded by surface biomass and protected by light-attenuating properties of the water itself. Thus, during high sunlight intensity, deeply mixed phytoplankton will fluoresce while shallowmixed biomass will be invisible to a fluorometer. If uncorrected, quenched fluorescence yields will generate values under-representative of phytoplankton abundance at the surface. Avoiding such under-representation is particularly important for studies comparing satellite-derived surface $\mathrm{Chl} a$ with in situ fluorescence-derived $\mathrm{Chl} a$.

On the vertical scale, quenched fluorescence profiles are also problematic in that they mimic the shape of true deep fluorescence maxima (DFM) (Mignot et al., 2011). Sub-surface fluorescence maxima can be indicative of deep chlorophyll maxima (DCM). These features either form due to differences in Chl $a$ packaging, or when the bulk of phytoplankton biomass settles to depths where both nutrients and light are sufficient (Cullen and Eppley, 1981; Holm-Hansen and Hewes, 2004; Mellard et al., 2011). Because DCM are found below one optical depth, abundance and distribution of such features cannot be measured by satellite (McClain, 2009; Charrassin et al., 2010). However, vertical distributions of phytoplankton play important roles in the organisation of pelagic trophic food webs (Mellard et al., 2011). DCM in particular play potentially under-reported roles in net primary production and carbon fixation (Fairbanks et al., 1982; Estrada et al., 1993; Claustre et al., 2008). It is therefore useful to try to accurately identify and map these features.

In previous work on glider data, correcting for quenching involved using backscatter (Sackmann et al., 2008) or surface light intensity (Todd et al., 2009), each measured simultaneously to fluorescence. For autonomous platforms collecting only fluorescence, salinity and temperature data in remote locations, this is not possible. Using the depth of the densityderived mixed layer, Xing et al. (2011) corrected quenched fluorescence data collected by Argo floats in Pacific, Atlantic and Mediterranean offshore zones. This mixed layer depth (MLD) method was then extended to fluorescence data collected by tagged southern elephant seals (Mirounga leonina) off Kerguelen Island in the Southern Ocean (Xing et al., 2012; Guinet et al., 2013). Following the method of Xing et al. (2012), the maximum fluorescence yield within the density-derived mixed layer would be representative of the whole, assuming homogeneity. How robust is this assumption for the waters of the Southern Ocean?

The upper layer of the Southern Ocean tends to be deeply mixed, even over austral summers, and DCM are thought to be rare (discussed in Holm-Hansen and Hewes, 2004). However, ship-based studies undertaken in different regions of the Southern Ocean have shown that mixing and settling patterns within and between functional types are dynamic (HolmHansen and Hewes, 2004; Mengesha et al., 1998; Quéguiner, 2013; Sangrà et al., 2014). This is especially true for motile (flagellated) and seasonally successive (heavily silicified) species (Mengesha et al., 1998; Quéguiner, 2013). Furthermore, even within homogenously mixed layers of biomass, Chl $a$ packaging has been shown to vary with depth, generating DCM (and DFM) independent of biomass (Behrenfeld and Boss, 2006). Reliance on the assumption of homogeneity is, therefore, possibly problematic.

In this paper, we present an alternative method to account for quenching without relying on homogeneity in the densityderived upper layer. Non-photochemical quenching is corrected using the limit of the euphotic zone $\left(Z_{\mathrm{eu}}\right)$, defined as the depth at which downward photosynthetic available radiation (PAR) is at $\sim 1 \%$ of the surface value (Shang et al., 2011; Soppa et al., 2013). At this level, light should be sufficient for photosynthesis (Ryther and Menzel, 1959; Morel and Berthon, 1989; Saulquin et al., 2013; Palmer et al., 2013) but too weak to cause quenching (Alderkamp et al., 2011; Ross et al., 2011). This method is applied to fluorescence data collected by 19 animal-borne fluorometer, conductivity, temperature and depth satellite-relayed data loggers (FCTDSRDLs) deployed in the Southern Ocean over several austral summers.

\section{Methods}

\subsection{In situ data}

Between 2009 and 201318 adult female southern elephant seals from Kerguelen and one from Marion Island were equipped with FCTD-SRDLs (Sea Mammal Research Unit, University of St Andrews, UK, Scotland) before they undertook their post-breeding foraging migration over the austral summer (Fig. 1). Following established tagging protocols 


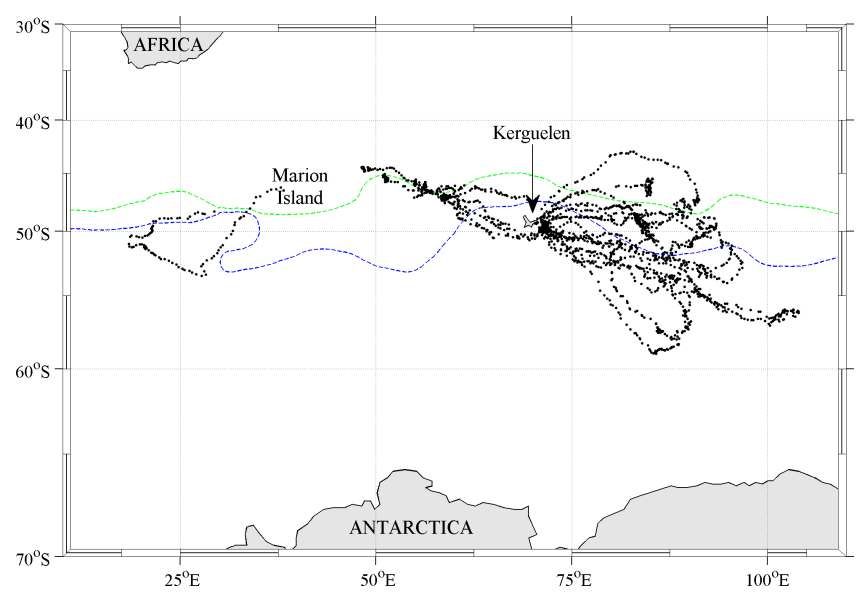

Figure 1. Tracks of 19 southern elephant seals tagged with FCTDSRDLs over austral summers from 2009 to 2013 in black. The general positions of the subantarctic front and the polar front are shown in green and blue, respectively (Orsi and Harris, 2014). The incomplete track seen off Marion Island is due to the FCTD-SRDL battery failing after 55 days.

(Bester, 1988; McIntyre et al., 2010), the seal on Marion Island was immobilised with ketamine using a remote injection method and the tag was glued to the fur on the head with quick-setting epoxy resin. Seals on Kerguelen were anesthetised with an intravenous injection of tiletamine and zolazepam $1: 1$ and tags were glued to the fur on the head using a two component industrial epoxy (Jaud et al., 2012).

The FCTD-SRDL instrument records behavioural data as well as in situ pressure, temperature, salinity and fluorescence (Charrassin et al., 2010; Xing et al., 2012). At-sea data were relayed via the Argos satellite system (http://www. argos-system.org). Locations were provided by Service Argos based on Doppler shift measurements and data were downloaded from the Sea Mammal Research Unit Instrumentation Group's website (http://www.smru.st-andrews.ac. $\mathrm{uk} /$ ). Detailed information on the hardware and software of the CTD-SRDL is described by Boehme et al. (2009), and on-board data processing is described comprehensively by Fedak et al. (2002).

Fluorescence is recorded by a Cyclops 7 fluorometer (Turner Designs, CA, USA), which delivers a voltage output proportional to the fluorescence detected in a wavelength between 620 and $715 \mathrm{~nm}$. The Cyclops instrument is programmed to measure fluorescence every $2 \mathrm{~s}$ during the ascent (upcast), from $180 \mathrm{~m}$ to the surface. Due to the tight limits on data transfer through the Argos satellite system, data have to be compressed (Boehme et al., 2009). Fluorescence yields were therefore binned into $10 \mathrm{~m}$ vertical intervals. The reading for $175 \mathrm{~m}$ is thus a weighted mean of all fluorescence readings taken between 180 and $170 \mathrm{~m}$. This is the deepest bin available - deep and dark enough to anticipate an absence of live, photosynthesising phytoplankton (Guinet et al.,
2013). However, instruments do not return readings of zero at these depths. This dark count is an offset value added by the manufacturers, and is useful because at very low signal, readings are indistinguishable from noise. The offset value increases the signal to noise ratio, which must be removed during data processing (Lavigne et al., 2012). We therefore calculated the median of readings at $175 \mathrm{~m}$ and subtracted this from all measurements collected by the same tag (Xing et al., 2011). This is not only useful for making the fluorescence values more representative, it also serves to reduce variability between tags (Xing et al., 2012). The resulting values are considered proportional to fluorescence, and are termed relative fluorescence units (RFU).

\subsection{Satellite data}

The depth of $Z_{\text {eu }}$ reflects the limit where PAR is $1 \%$ of its surface value. In this study, we use an estimate of the euphotic zone $Z_{\mathrm{eu}}$ based on an algorithm by Lee et al. (2007). These estimates are derived from measurements of the water-leaving radiance by the Moderate Imaging Spectrometer (MODIS) as $4 \mathrm{~km} \times 4 \mathrm{~km}$ monthly composites (http: //oceancolor.gsfc.nasa.gov).

To optimise temporal and spatial coverage in a region as cloudy as the Southern Ocean, values of L3 8 day $Z_{\mathrm{eu}}$ were used whenever available, and values from monthly composites were then added to fill in the blanks. However, despite the broad coverage in time, gaps were still present in space. For each fluorometer profile the closest $Z_{\text {eu }}$ value in space was extracted from the gridded data set. If no value was available, $Z_{\mathrm{eu}}$ was interpolated linearly from the nearest seal position with an associated $Z_{\text {eu }}$ value.

\subsection{Correcting for quenching}

Quenching occurs in surface waters during periods of high light stress. Despite daily variability attributed to cloud (changing light intensity), and differences in phytoplankton concentrations between years and regions, suppression of fluorescence is a ubiquitous feature. Fitting a non-linear model ( $\sin$ function) to surface fluorescence as a function of time of day showed that quenching around midday was significant $\left(n=1267, R^{2}=0.26, P<0.001\right)$ (Supplement Fig. S1). Data were thus categorised as day: possibly quenched (from sunrise to sunset, with the sun 8 degrees above the horizon) or night: unquenched. To illustrate the quenching effect without interannual and regional variability, day yields were divided by the preceding night yields to generate ratios. Data were then binned by hour and plotted using box plots (Fig. 2).

Before processing, a small proportion of profiles with maximum fluorescence yields below 0.15 RFU were removed from the data set. These low signals tend to fall within the noise, and the resulting vertical profiles cannot be meaningfully interpreted. 

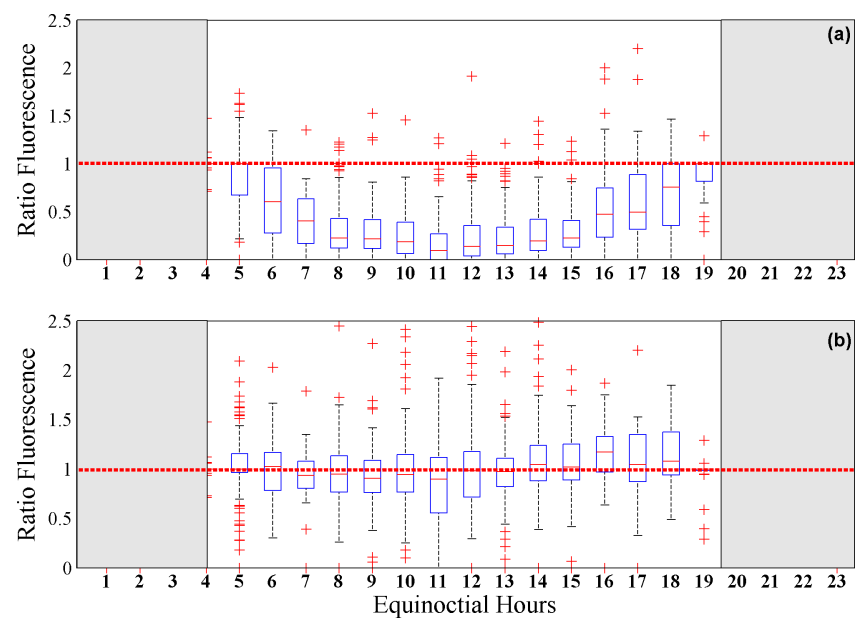

Figure 2. Ratio of day to night surface fluorescence yield (first $15 \mathrm{~m}$ ) per local hour from data collected by 19 animal-borne fluorometers over five austral summers. Box plots show the distribution of day to night ratios in (a), representing quenched to unquenched yield, respectively. The horizontal red line at 1 indicates the $1: 1$ ratio. Ratios of fluorescence yield decrease from around 06:00 until around 18:00 LT, then recover to the $1: 1$ ratio line. Corrected ratios of fluorescence in (b) do not follow the same trend of deviation from the $1: 1$ ratio line at 1 . Flanking grey sections represent times of the day where the sun is less than 6 degrees below the horizon.

The night: unquenched data were then normalised and each profile was interrogated for maximum values below the near-surface yield. To ensure a deep maximum value is not within the measurement error for each tag, a $95 \%$ confidence interval for the error was calculated for each instrument using bootstrapping (1000 bootstrap samples). The upper confidence limit was set as a threshold value, subtracted from the deep maximum and added to the near-surface value. Only differences outside of this threshold were flagged as potential DFM, and these profiles were then visually inspected. Vertical profiles conforming to the shape of DFM in this data set were considered true DFM, independent of quenching (Fig. S2).

For the day: quenched data, we compare the results of fluorescence quenching correction from two depths. The first is a density-derived MLD calculated from the concurrent CTD measurements of the FCTD-SRDL. Here, MLD is defined as the depth where the vertical density gradient equals or exceeds a threshold value of $\Delta \rho=0.03 \mathrm{~kg} \mathrm{~m}^{-3}$; as employed by Xing et al. $(2011,2012)$ (de Boyer Montégut et al., 2004; Kara et al., 2000). The MLD in the region of interest tends to remain deeper than $50 \mathrm{~m}$, even over the austral summer (Dong et al., 2008; Fig. 3). The second depth is the remotely derived $Z_{\text {eu }}$ using Lee's algorithm (2007). Separately, maximum fluorescence yield between MLD and the surface, or $Z_{\mathrm{eu}}$ and the surface, were then extended to fill in suppressed yield (Fig. 3).
For over $80 \%$ of the day data set, mixed layer depth was deeper than $Z_{\mathrm{eu}}$. However, the small proportion $(\sim 20 \%)$ of waters with MLD shallower than $Z_{\text {eu }}$ proved problematic for correcting quenching. In these instances, correcting from MLD generates still-quenched values. Conversely, correcting from $Z_{\text {eu }}$ would mask shallow but potentially true subsurface features. Where MLD shoaled above $Z_{\text {eu }}$, fluorescence data were thus flagged and removed from the data set.

\section{Results}

The at-sea phases of the 19 tagged southern elephant seals (Fig. 1) tended to start in November and end in late January of the following year, meaning data were collected over the height of the austral summer. In the top 10-15 $\mathrm{m}$ of the upper mixed layer across all years of sampling, suppression of daytime fluorescence yield was significant (Fig. 2a).

To correct for quenching in deeply mixed waters, surface values collected between dawn and dusk were filled in with maximum values from the depth of the mixed layer, or the depth of $Z_{\mathrm{eu}}$. The difference between these methods is illustrated in Fig. 3, where individual normalised fluorescence profiles are treated with the two correction schemes. Corrected surface fluorescence yields are overestimated using the depth of the mixed layer, but perhaps more importantly, vertical complexity is lost. Correcting from $Z_{\mathrm{eu}}$ serves to conserve unusual (not homogenous) dynamics on the vertical scale. This is illustrated in Fig. 3b, where phyotoplankton may either be settling into different layers (floristic shifts) or where Chl $a$ packaging has become measurably different between deep-mixed and shallow-mixed layers (photoacclimation).

The difference between the two methods is also evident looking at fluorescence sections in Fig. 4. Uncorrected vertical profiles in the top row (Fig. 4a, d and g) illustrate how evident suppression of daytime fluorescence yield is in the surface layers (greyscale bar with daylight hours in white and black for night). Quenching is corrected using MLD in the second row (Fig. $4 \mathrm{~b}$, e and $\mathrm{h}$ ) and $Z_{\mathrm{eu}}$ in the third (Fig. 4c, f and i). The distinct subsurface fluorescence feature in (a) is within the mixed layer, and is thus masked when corrected from this depth (b). However, correcting from $Z_{\text {eu }}$ conserves vertical complexity while still correcting quenching at the surface (c). The deep fluorescence feature in Fig. 4d also has a maximal yield below euphotic depth but within the mixed layer. This deep signal is masked when correcting from MLD (e) but remains distinct when using $Z_{\text {eu }}$ (f). Finally, the dynamics in Fig. $4 \mathrm{~g}$ are lost when correcting from the depth of the mixed layer (h) but conserved when correcting from $Z_{\mathrm{eu}}$ (i). The night data from this example in particular corroborates complex Chl $a$ dynamics with depth.

Unquenched fluorescence profiles collected at night support the evidence that DCM should be accounted for in this oceanic regime. Of the 19 seals tagged with FCTD-SRDLs 


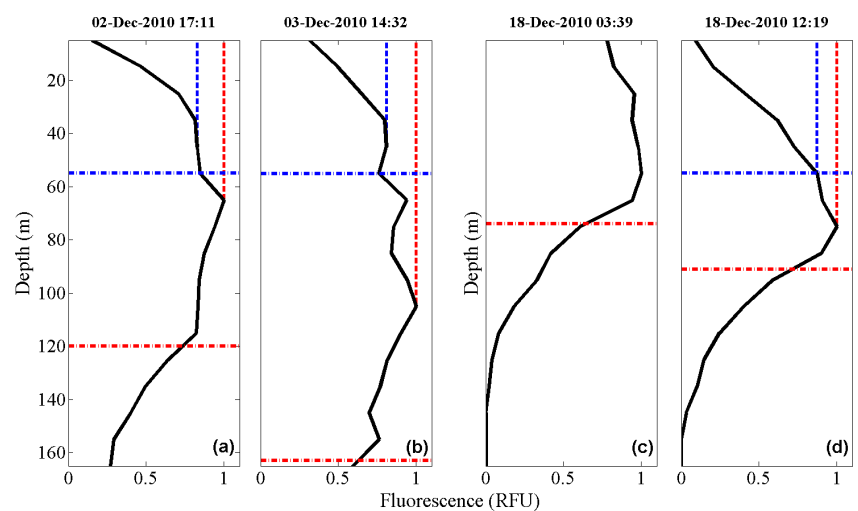

Figure 3. Normalised vertical profiles of fluorescence (solid black line) corrected using either the depth of the mixed layer (dashed red line) or the $1 \%$ light level, $Z_{\mathrm{eu}}$ (dashed blue line). The fluorescence in profile (c) was measured at night and is unquenched (mixed layer is shown by the dashed red line but $Z_{\mathrm{eu}}$ is absent at night). Profiles (a), (b) and (d) were collected at varying times during the day. For each profile, quenched fluorescence is corrected using either $Z_{\mathrm{eu}}$ (depth and corresponding fluorescence yield shown with dashed blue line) or MLD (depth and corresponding fluorescence yield shown with dashed red line).

between 2009 and 2013, 18 instruments measured DFM in the night (unquenched) data. For the combined night data set, approximately $30 \%$ of the 797 profiles showed DFM $($ mean $=13$; standard deviation $=9)$ (Fig. S3). Correcting with $Z_{\text {eu }}$ doubled the number of DFM conserved in the day data (21\%) compared with MLD (10\%), but was still unable to fully match the percentage found in the night data.

\section{Discussion}

The phenomenon of non-photochemical quenching is well described and appears to be ubiquitous across oceans and seasons (Sackmann et al., 2008; Milligan et al., 2012). The depth where light levels are sufficient for photosynthesis but too weak to generate quenching is key for correcting in situ fluorescence data; ensuring fluorescence yield is representative of vertical Chl $a$ concentrations. However, when fluorescence data are collected autonomously, this depth cannot always be measured in space and time.

For this study, removing quenched fluorescence would mean discarding 1352 of the 2149 profiles collected by 19 animal-borne tags over several austral summers in the Southern Ocean. Losing over $60 \%$ of the data collected from such an undersampled region is simply not viable. Thus, two proxy depths are compared for quenching correction. The first is a density-derived MLD, calculated from CTD data measured concurrently by the tag (Xing et al., 2012; Guinet et al., 2013). The second is the depth of the remotely derived euphotic zone, $Z_{\text {eu }}$ (Lee et al., 2007).
During daylight hours, a proportion of the euphotic zone (defined as the surface to the $1 \%$ light level) will be lightsaturated relative to photosynthetic efficiency (Behrenfeld and Falkowski, 1997). Shallow-mixed phytoplankton are exposed to a range of super-saturating light intensities, while deep-mixed phytoplankton will be exposed to low-levels of light intensity that are suboptimal for photosynthesis in the absence of photoadaptation.

Cells throughout any given euphotic zone adapt to variations in the light field through a range of physiological strategies (Arrigo et al., 2010; Kropuenske et al., 2009, 2010). These include non-photochemical quenching for high light stress, and a range of dark adaptation strategies below a saturating light threshold. Photosynthesis typically saturates at light intensities of $\sim 200 \mathrm{mmol}$ photons $\mathrm{m}^{-2} \mathrm{~s}^{-1}$ (van der Poll et al., 2009) and below $\sim 100$ mmol photons $\mathrm{m}^{-2} \mathrm{~s}^{-1}$ cells must initiate dark adaptation strategies (Garcia and Purdie, 1992). By definition, such dark-adapted phytoplankton at the base of the euphotic zone are not experiencing high light stress. However, light is still sufficient for photosynthesis. Indeed, Hameedi (1978), Platt et al. (1982) and Lee et al. (2010) have shown that shade-acclimated phytoplankton from the $1 \%$ light level are more productive than phytoplankton from the 50\% light level (Alderkamp et al., 2011; Palmer et al., 2013).

At noon on a cloudless summer's day, the Southern Ocean can receive surface irradiance of up to $2000 \mathrm{mmol}$ photons $\mathrm{m}^{-2} \mathrm{~s}^{-1}$ (Ross et al., 2008). Light saturation would be expected at $10 \%$ surface light levels, while dark-adapted phytoplankton would be found at $\sim 5 \%$ of the maximal expected surface irradiance. Therefore, at the $1 \%$ light level, phytoplankton are likely dark adapted (i.e. not exhibiting non-photochemical quenching) and actively photosynthesizing.

Composites of MODIS $Z_{\text {eu }}$ are provided as evaluative products and these were used to determine euphotic depth, where light intensity would be too low to cause light stress and suppression of fluorescence yield. Lee's algorithm for $Z_{\text {eu }}$ provided accurate and reliable estimates of $Z_{\text {eu }}$ in open waters of the China Sea (Morel, 1988; Morel et al., 2007; Lee et al., 2007; Shang et al., 2011). We assume that this method can also reliably estimate the limit of the euphotic zone in the open waters of the Southern Ocean. However, validation with in situ light data at the high latitudes would be beneficial for measuring the accuracy of this product.

Combinations of 8 day and monthly $Z_{\text {eu }}$ products were used to account for the gaps in coverage. Satellites cannot see through clouds, and the high latitudes are persistently cloudy. Despite the large temporal difference, 8 day and monthly products showed excellent agreement $\left(R^{2}=0.82\right.$, $p<0.0001)$. This is less likely to be true for coastal or nearcoastal regimes, where dynamics change on finer scales. For this reason, we would recommend using daily data combined with 8 day composites in these areas, or any region where cloud cover is less of a persistent problem. As a compro- 

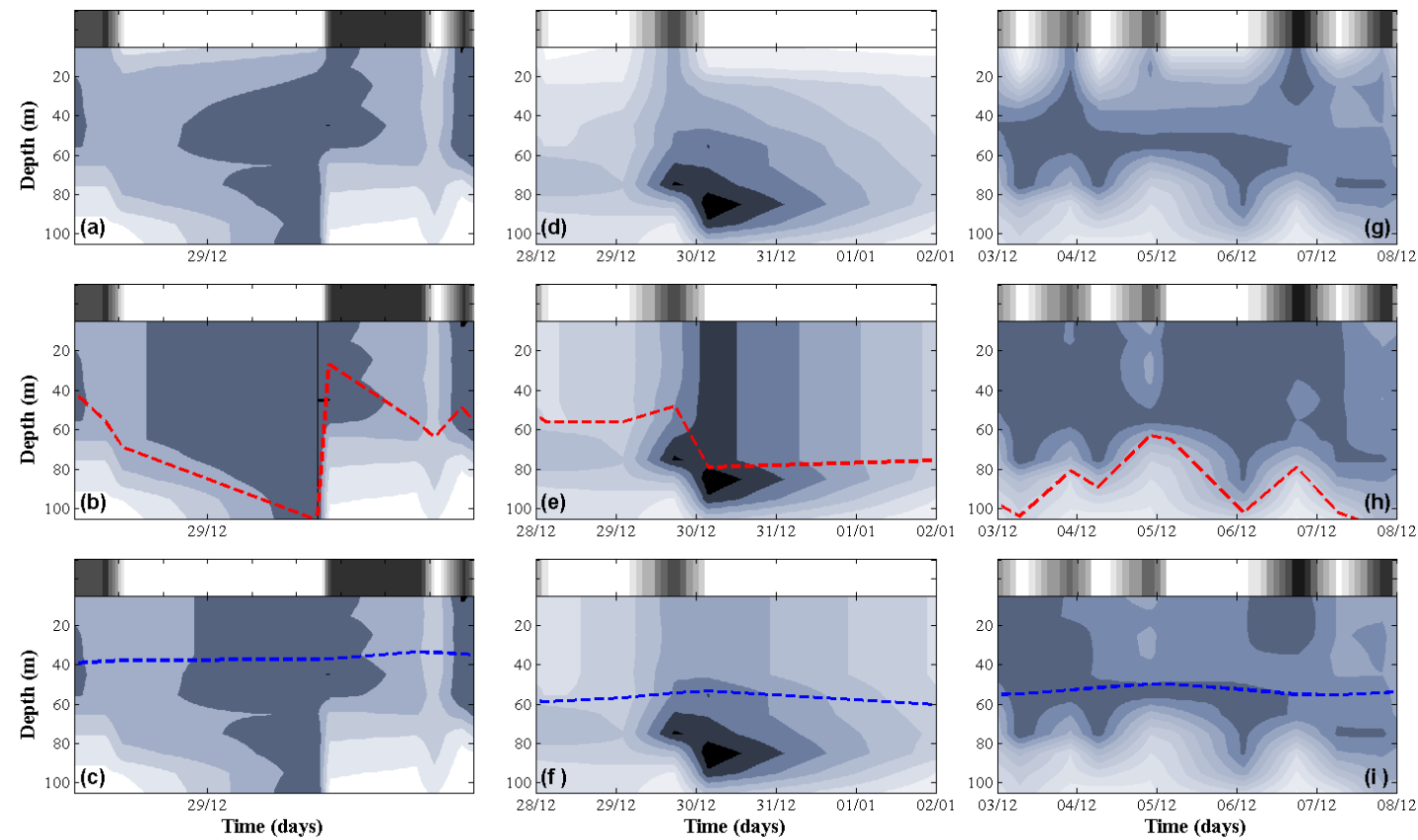

(RFU)

Figure 4. Sections of fluorescence corrected using either the depth of the mixed layer (dashed red line) or the depth of the $1 \%$ light level, $Z_{\text {eu }}$ (dashed blue line). The greyscale bar attached to the top of each plot illustrates when fluorescence data were collected relative to the time of day, with black for night and white for day. The top row of vertical profiles (a), (d) and (g) show sections of uncorrected fluorescence data collected by different instrumented seals over austral summers. The fluorescence data in the second row (b), (e) and (h) have been corrected using mixed layer depth. The last row of fluorescence data (c), (f) and (i) have been corrected using euphotic depth. Conditions where MLD shoals above $Z_{\mathrm{eu}}$ cannot be corrected and have been filtered from the day data set, but not from the night (unquenched).

mise, generating 16-day composites using SeaDAS 7.0 (Fu et al., 1998) would address the temporal compromise as well as fill in some of the gaps. However, this step requires custom processing, rather than the use of freely available and pre-existing products. This may limit wider application of the method. Our aim is to create a method that is easily applied and universally useful for autonomously collected fluorescence data in regions where waters tend to be deeply mixed.

Surface waters of the Antarctic are deeply mixed and deep chlorophyll maxima were previously thought to be rare (Holm-Hansen and Hewes, 2004). However, while the vertical distribution of phytoplankton is controlled by turbulence and density, it is also driven by nutrient and light gradients (Navarro et al., 2006). Cell motility has been shown to prevail over dispersion by turbulence (Durham et al., 2013). When ideal levels of light and nutrients change with depth over time, so too will the vertical distribution of biomass in the water column (evolutionary stable strategy depth) (Mellard et al., 2011). Indeed, 19 of the 19 seals tagged with FCTDSRDLs between 2009 and 2013 returned DFM in the night data. These in situ fluorescence data sets add to growing evidence that DCM may be regionally and seasonally persistent in the Southern Ocean (Holm-Hansen et al., 2005; Charrassin et al., 2010; Quéguiner, 2013).
Distinct DCM are only a part of the story, however. Heterogeneous phytoplankton patterns within layers of homogenous density are a common feature of the North Atlantic, resulting from slow mixing rates (relative to growth rates) during periods without deep convective mixing (Taylor and Ferrari, 2011). Although we have no information on mixing or turbulence, finding deep maxima in $30 \%$ of the night data points to moderate or even weak turbulence in the upper layer (Ross et al., 2011; Franks, 2014). Correcting from $Z_{\text {eu }}$ serves to conserve unusual (not homogenous) dynamics between the $1 \%$ light level and MLD. From a biological perspective, this vertical information may provide useful insights into mixing and settling patterns of different phytoplankton species (floristic shifts), or differences in chlorophyll packaging in the same species (photoacclimation). However, the fact that DCM and non-uniform phytoplankton patterns persist over the five summers recorded may also be interesting from a purely physical perspective.

The problem of phytoplankton not being uniformly distributed in the mixed layer was commented on by Xing et al. (2011), but not addressed until now. The limitations of our own correction scheme would be improved with testing of the accuracy of the remotely sensed $Z_{\text {eu }}$ product in Southern Ocean waters with in situ light data. Furthermore, until we are able to apply our quenching method to fluorescence data 
outside of the high latitudes, we are only able to suggest that using $Z_{\text {eu }}$ improves the current method in the deeply mixed waters of the Southern Ocean.

\section{The Supplement related to this article is available online at doi:10.5194/os-12-83-2015-supplement.}

Acknowledgements. This work received funding from the MASTS pooling initiative (The Marine Alliance for Science and Technology for Scotland) and their support is gratefully acknowledged. MASTS is funded by the Scottish Funding Council (grant reference HR09011) and contributing institutions. A number of field assistants were involved in the deployment of tags on Marion and we are particularly grateful to Mia Wege. FCTD-SRDL tags and fluorescence data were generously provided by CEBC-CNRS as part of the research program supported by CNES-TOSCA, ANR-VMC, Total Foundation and IPEV. The Mammal Research Institute, University of Pretoria, covered Marion Island Argos transmission costs and we thank Trevor McIntyre for facilitating this. We are grateful to Sandy Thomalla and other reviewers for significantly improving this manuscript. Special thanks to Drew Lucas, Mick Wu and Hayley Evers-King for their assistance with the editing, statistics and bio-optics, respectively.

Edited by: M. Hoppema

\section{References}

Alderkamp, A. C., Garcon, V., de Baar, H. J., and Arrigo, K. R.: Short-term photoacclimation effects on photoinhibition of phytoplankton in the Drake Passage (Southern Ocean), Deep Sea Res. Pt. I, 58, 943-955, doi:10.1016/j.dsr.2011.07.001, 2011.

Arrigo, K. R., Mills, M. M., Kropuenske, L. R., van Dijken, G. L., Alderkamp, A. C., and Robinson, D. H.: Photophysiology in two major Southern Ocean phytoplankton taxa: photosynthesis and growth of Phaeocystis antarctica and Fragilariopsis cylindrus under different irradiance levels, Integr. Comp. Biol., 50, 950-966, doi:10.1093/icb/icq021, 2010.

Behrenfeld, M. J. and Boss, E.: Beam attenuation and chlorophyll concentration as alternative optical indices of phytoplankton biomass, J. Mar. Res., 64, 431-451, doi:10.1357/002224006778189563, 2006.

Behrenfeld, M. J. and Falkowski, P. G.: Photosynthetic rates derived from satellite-based chlorophyll concentration, Limnol. Oceanogr., 42, 1-20, doi:10.4319/1o.1997.42.1.0001, 1997.

Behrenfeld, M. J., Westberry, T. K., Boss, E. S., O’Malley, R. T., Siegel, D. A., Wiggert, J. D., Franz, B. A., McClain, C. R., Feldman, G. C., Doney, S. C., Moore, J. K., Dall'Olmo, G., Milligan, A. J., Lima, I., and Mahowald, N.: Satellite-detected fluorescence reveals global physiology of ocean phytoplankton, Biogeosciences, 6, 779-794, doi:10.5194/bg-6-779-2009, 2009.

Bester, M. N.: Chemical restraint of Antarctic fur seals and southern elephant seals, South Afr. J. Wildl. Res., 18, 57-60, 1988.
Boehme, L., Lovell, P., Biuw, M., Roquet, F., Nicholson, J., Thorpe, S. E., Meredith, M. P., and Fedak, M.: Technical Note: Animalborne CTD-Satellite Relay Data Loggers for real-time oceanographic data collection, Ocean Sci., 5, 685-695, doi:10.5194/os5-685-2009, 2009.

Charrassin, J. B., Roquet, F., Park, Y. H., Bailleul, F., Guinet, C., Meredith, M., , Nicholls, K., Thorpe, S., Tremblay, Y., Costa, D., Göbel, M., Muelbert, M., Bester, M. N., Plötz, J., Bornemann, H., Timmermann, R., Hindell, M., Meijers, A., Coleman, R. C., Field, I. C., McMahon, C., Rintoul, S., Sokolov, S., Fedak, M., Lovell, P., Biuw, M., Kovacs, K., and Lydersen, C.: New insights into Southern Ocean physical and biological processes revealed by instrumented elephant seals, Proceedings of OceanObs 09: Sustained Ocean Observations and Information for Society (Vol. 2), edited by: Hall, J., Harrison, D. E., and Stammer, D., Venice, Italy, 21-25 September 2009, doi:10.5270/OceanObs09.cwp.15, ESA Publication WPP-306, 2010.

Claustre, H., Sciandra, A., and Vaulot, D.: Introduction to the special section bio-optical and biogeochemical conditions in the South East Pacific in late 2004: the BIOSOPE program, Biogeosciences, 5, 679-691, doi:10.5194/bg-5-679-2008, 2008.

Cullen, J. J. and Eppley, R. W.: Chlorophyll maximum layers of the Southern-California Bight and possible mechanisms of their formation and maintenance, Oceanologica Acta, 4, 23-32, 1981.

de Boyer Montégut, C., Madec, G., Fischer, A. S., Lazar, A., and Iudicone, D.: Mixed layer depth over the global ocean: An examination of profile data and a profile-based climatology, J. Geophys. Res.-Ocean., (1978-2012), 109, C12003, doi:10.1029/2004JC002378, 2004.

Dierssen, H. M. and Smith, R. C.: Bio-optical properties and remote sensing ocean color algorithms for Antarctic Peninsula waters, J. Geophys. Res.-Ocean., (1978-2012), 105, 26301-26312, doi:10.1029/1999JC000296, 2000.

Dong, S., Sprintall, J., Gille, S. T., and Talley, L.: Southern Ocean mixed?layer depth from Argo float profiles, J. Geophys. Res.Oceans, 113, C06013, doi:10.1029/2006JC004051, 2008.

Durham, W. M., Climent, E., Barry, M., De Lillo, F., Boffetta, G., Cencini, M., and Stocker, R.: Turbulence drives microscale patches of motile phytoplankton, Nature communications, 4, 2148, doi:10.1038/ncomms3148, 2013.

Estrada, M., Marrase, C., Latasa, M., Berdalet, E., Delgado, M., and Riera, T.: Variability of deep chlorophyll maximum characteristics in the Northwestern Mediterranean, Marine Ecol. Progr. Ser., 92, 289-289, 1993

Fairbanks, R. G., Sverdlove, M., Free, R., Wiebe, P. H., and Bé, A. W.: Vertical distribution and isotopic fractionation of living planktonic foraminifera from the Panama Basin, Nature, 298, 841-844, 1982.

Falkowski, P. G. and Kolber, Z.: Variations in Chlorophyll Fluorescence Yields in Phytoplankton in the World Oceans, Austr. J. Plant Physiol., 22, 341-355, 1995.

Falkowski, P. G., Barber, R. T., and Smetack, V.: Biogeochemical controls and feedbacks on ocean primary productivity, Science, 281, 200-206, 1998.

Fedak, M., Lovell, P., McConnell, B., and Hunter, C.: Overcoming the constraints of long range radio telemetry from animals: getting more useful data from smaller packages, Integr. Comparat. Biol., 42, 3-10, doi:10.1093/icb/42.1.3, 2002. 
Franks, P. J.: Has Sverdrup's critical depth hypothesis been tested? Mixed layers vs. turbulent layers, ICES J. Mar. Sci., doi:10.1093/icesjms/fsu175, online firstm, 2014.

Fu, G., Baith, K. S., and McClain, C. R.: SeaDAS: The SeaWiFS Data Analysis System, Proceedings of The 4th Pacific Ocean Remote Sensing Conference, Qingdao, China, 28-31 July, 73-79, 1998.

Garcia, V. M. T. and Purdie, D. A.: The influence of irradiance on growth, photosynthesis and respiration of Gyrodinium cf. aureolum, J. Plankton Res., 14, 1251-1265, 1992.

Gordon, H. R. and Morel, A.: Remote Sensing of Ocean Color for Interpretation of Satellite Visible Imagery: A Review, (SpringerVerlag, New York), 1983.

Guinet, C., Xing, X., Walker, E., Monestiez, P., Marchand, S., Picard, B., Jaud, T., Authier, M., Cotté, C., Dragon, A. C., Diamond, E., Antoine, D., Lovell, P., Blain, S., D’Ortenzio, F., and Claustre, H.: Calibration procedures and first dataset of Southern Ocean chlorophyll a profiles collected by elephant seals equipped with a newly developed CTD-fluorescence tags, Earth Syst. Sci. Data, 5, 15-29, doi:10.5194/essd-5-15-2013, 2013.

Hameedi, M. J.: Aspects of water column primary productivity in the Chukchi Sea during summer, Marine Biol., 48, 37-46, 1978.

Henson, S. A., Sarmiento, J. L., Dunne, J. P., Bopp, L., Lima, I., Doney, S. C., John, J., and Beaulieu, C.: Detection of anthropogenic climate change in satellite records of ocean chlorophyll and productivity, Biogeosciences, 7, 621-640, doi:10.5194/bg-7621-2010, 2010.

Holm-Hansen, O. and Hewes, C. D.: Deep chlorophyll $a$ maxima (DCMs) in Antarctic waters, Polar Biol., 27, 699-710, doi:10.1007/s00300-004-0641-1, 2004.

Holm-Hansen, O., Kahru, M., and Hewes, C. D.: Deep chlorophyll a maxima (DCMs) in pelagic Antarctic waters. II. Relation to bathymetric features and dissolved iron concentrations, Marine Ecol. Progr. Ser., 297, 71-81, doi:10.3354/meps297071, 2005.

Jaud, T., Dragon, A. C., Garcia, J. V., and Guinet, C.: Relationship between Chlorophyll a Concentration, Light Attenuation and Diving Depth of the Southern Elephant Seal Mirounga leonina, PLoS one, 7, e47444, doi:10.1371/journal.pone.0047444, 2012.

Johnson, K. S., Berelson, W. M., Boss, E. S., Chase, Z., Claustre, H., Emerson, S. R., Gruber, N., Kortzinger, A., Perry, M. J., and Riser, S. C.: Observing Biogeochemical Cycles at Global Scales with Profiling Floats and Gliders: Prospects for a Global Array, Oceanography, 22, 216-225, doi:10.5670/oceanog.2009.81, 2009.

Kropuenske, L. R., Mills, M. M., van Dijken, G. L., Bailey, S., Robinson, D. H., Welschmeyer, N. A., and Arrigo, K. R.: Photophysiology in two major Southern Ocean phytoplankton taxa: photoprotection in Phaeocystis antarctica and Fragilariopsis cylindrus, Limnol. Oceanogr., 54, 1176, doi:10.1111/j.15298817.2010.00922.x, 2009.

Kropuenske, L. R., Mills, M. M., Van Dijken, G. L., Alderkamp, A. C., Mine Berg, G., Robinson, D. H., Welschmeyer, N. A., and Arrigo, K. R.: Strategies And Rates Of Photoacclimation In Two Major Southern Ocean Phytoplankton Taxa: Phaeocystis Antarctica (Haptophyta) And Fragilariopsis Cylindrus (Bacillariophyceae) 1, J. Phycol., 46, 1138-1151, 2010.

Lavigne, H., D’Ortenzio, F., Claustre, H., and Poteau, A.: Towards a merged satellite and in situ fluorescence ocean chlorophyll product, Biogeosciences, 9, 2111-2125, doi:10.5194/bg-9-21112012, 2012.

Lee, S. H., Stockwell, D., and Whitledge, T. E.: Uptake rates of dissolved inorganic carbon and nitrogen by under-ice phytoplankton in the Canada Basin in summer 2005, Polar Biol., 33, 1027-1036, 2010.

Lee, Z., Weidemann, A., Kindle, J., Arnone, R., Carder, K. L., and Davis, C.: Euphotic zone depth: Its derivation and implication to ocean-color remote sensing, J. Geophys. Res.-Oceans (19782012), 112, 223-227, doi:10.1016/0011-7471(66)91102-8, 2007.

Lorenzen, C. J.: A method for the continuous measurement of in vivo chlorophyll concentration, Deep Sea Res. Oceanogr. Abstr., 13, 223-227, 1966.

Lorenzen, C. J. and Jeffrey, S. W.: Determination of chlorophyll in seawater, Unesco tech. pap. Mar. Sci., 35, 1-21, 1980.

McClain, C. R.: A Decade of Satellite Ocean Colour Observations, Ann. Rev. Marine Sci., 1, 19-22, 2009.

McIntyre, T., de Bruyn, P. J. N., Ansorge, I. J., Bester, M. N., Bornemann, H., Plötz, J., and Tosh, C. A.: A lifetime at depth: vertical distribution of southern elephant seals in the water column, Polar Biol., 33, 1037-1048, 2010.

Mellard, J. P., Yoshiyama, K., Litchman, E., and Klausmeier, C. A.: The vertical distribution of phytoplankton in stratified water columns, J. Theor. Biol., 269, 16-30, doi:10.1016/j.jtbi.2010.09.041, 2011.

Mengesha, S., Dehairs, F., Fiala, M., Elskens, M., and Goeyens, L.: Seasonal variation of phytoplankton community structure and nitrogen uptake regime in the Indian Sector of the Southern Ocean, Polar Biol., 20, 259-272, 1998.

Mignot, A., Claustre, H., D’Ortenzio, F., Xing, X., Poteau, A., and Ras, J.: From the shape of the vertical profile of in vivo fluorescence to Chlorophyll-a concentration, Biogeosciences, 8, 23912406, doi:10.5194/bg-8-2391-2011, 2011.

Milligan, A. J., Aparicio, U. A., and Behrenfeld, M. J.: Fluorescence and nonphotochemical quenching responses to simulated vertical mixing in the marine diatom Thalassiosira weissflogii, Mar. Ecol. Progr. Ser., 448, 67-78, doi:10.3354/meps09544, 2012.

Morel, A.: Optical modeling of the upper ocean in relation to its biogenous matter content (case I waters), J. Geophys. Res.Ocean., 93, 10749-10768, 1988.

Morel, A. and Berthon, J. F.: Surface pigments, algal biomass profiles, and potential production of the euphotic layer: Relationships reinvestigated in view of remote-sensing applications, Limnol. Oceanogr., 34, 1545-1562, 1989.

Morel, A. and Prieur, L.: Analysis of variations in ocean color, Limnol. Oceanogr., 22, 709-722, 1977.

Morel, A., Huot, Y., Gentili, B., Werdell, P. J., Hooker, S. B., and Franz, B. A.: Examining the consistency of products derived from various ocean color sensors in open ocean (Case 1) waters in the perspective of a multi-sensor approach, Remote Sens. Environ., 111, 69-88, doi:10.1016/j.rse.2007.03.012, 2007.

Müller, P., Li, X. P., and Niyogi, K. K.: Non-photochemical quenching. A response to excess light energy, Plant Physiol., 125, 15581566, 2001.

Navarro, G., Ruiz, J., Huertas, I. E., García, C. M., CriadoAldeanueva, F., and Echevarría, F.: Basin-scale structures governing the position of the deep fluorescence maximum in the Gulf of Cádiz, Deep Sea Res. Pt II, 53, 1261-1281, 2006. 
Orsi, A. H. and Harris, U.: Locations of the various fronts in the Southern Ocean Australian Antarctic Data Centre-CAASM Metadata, 2001, available at: https://data.aad.gov.au/aadc/metadata/metadata_redirect.cfm? md=/AMD/AU/southern_ocean_fronts, 15, 1835-1852, updated 2014.

Palmer, M. A., van Dijken, G. L., Mitchell, B. G., Seegers, B. J., Lowry, K. E., Mills, M. M., and Arrigo, K. R.: Light and nutrient control of photosynthesis in natural phytoplankton populations from the Chukchi and Beaufort seas, Arctic Ocean, Limnol. Oceanogr., 58, 2185-2205, 2013.

Platt, T., Harrison, W. G., Irwin, B., Horne, E. P., and Gallegos, C. L.: Photosynthesis and photoadaptation of marine phytoplankton in the Arctic, Deep Sea Res. Pt A, 29, 1159-1170, 1982.

Quéguiner, B.: Iron fertilization and the structure of planktonic communities in high nutrient regions of the Southern Ocean. Deep Sea Res. Pt II, 90, 43-54, doi:10.1016/j.dsr2.2012.07.024, 2013.

Ross, O. N., Moore, C. M., Suggett, D. J., MacIntyre, H. L., and Geider, R. J.: A model of photosynthesis and photo-protection based on reaction center damage and repair, Limnol. Oceanogr., 53, 1835, doi:10.1029/2008JC005086, 2008.

Ross, O. N., Geider, R. J., Berdalet, E., Artigas, M. L., and Piera, J.: Modelling the effect of vertical mixing on bottle incubations for determining in situ phytoplankton dynamics. I. Growth rates, Marine Ecol. Progr. Ser., 435, 33-45, 2011.

Ryther, J. H. and Menzel, D. W.: Light adaptation by marine phytoplankton, Limnol. Oceanogr., 4, 492-497, 1959.

Sackmann, B. S., Perry, M. J., and Eriksen, C. C.: Seaglider observations of variability in daytime fluorescence quenching of chlorophyll-a in Northeastern Pacific coastal waters, Biogeosciences Discuss., 5, 2839-2865, doi:10.5194/bgd-5-2839-2008, 2008.

Sangrà, P., García-Muñoz, C., García, C. M., Marrero-Díaz, A., Sobrino, C., Mouriño-Carballido, B., Aguiar-González, B., Henríquez-Pastene, C., Rodríguez, S. A., Lubian, L., Hernández, M., Hernández-León, S., Vázquez, E., and Estrada-Allis, S. N.: Coupling between upper ocean layer variability and sizefractionated phytoplankton in a non-nutrient-limited environment, Marine Ecol. Progr. Ser., 499, 35-46, 2014.
Saulquin, B., Hamdi, A., Gohin, F., Populus, J., Mangin, A., and d'Andon, O. F.: Estimation of the diffuse attenuation coefficient $\mathrm{K}(\mathrm{dPAR})$ using MERIS and application to seabed habitat mapping, Remote Sens. Environ., 128, 224-233, 2013.

Shang, S., Lee, Z., and Wei, G.: Characterization of MODIS-derived euphotic zone depth: Results for the China Sea, Remote Sens. Environ., 115, 180-186, 2011.

Soppa, M. A., Dinter, T., Taylor, B. B., and Bracher, A.: Satellite derived euphotic depth in the Southern Ocean: Implications for primary production modelling, Remote Sens. Environ., 137, 198211, doi:10.1016/j.rse.2013.06.017, 2013.

Taylor, J. R. and Ferrari, R.: Shutdown of turbulent convection as a new criterion for the onset of spring phytoplankton blooms, Limnol. Oceanogr., 56, 2293-2307, doi:10.4319/lo.2011.56.6.2293, 2011.

Todd, R. E., Rudnick, D. L., and Davis, R. E.: Monitoring the greater San Pedro Bay region using autonomous underwater gliders during fall of 2006, J. Geophys. Res.-Ocean., 114, 483-495, doi:10.1029/2008JC005086, 2009. 2009.

van de Poll, W. H. and Buma, A. G. J.: Does ultraviolet radiation affect the xanthophyll cycle in marine phytoplankton?, Photochem Photobiol. Sci., 8, 1295-1301, doi:10.1039/b904501e, 2009.

Xing, X., Morel, A., Claustre, H., Antoine, D., D'Ortenzio, F., Poteau, A., and Mignot, A.: Combined processing and mutual interpretation of radiometry and fluorimetry from autonomous profiling Bio-Argo floats: Chlorophyll a retrieval, J. Geophys. Res.Oceans, (1978-2012), 116, doi:10.1029/2010JC006899, 2011.

Xing, X., Claustre, H., Blain, S., D’Ortenzio, F., Antoine, D., Ras, J., and Guinet, C.: Quenching correction for in vivo chlorophyll fluorescence acquired by autonomous platforms: A case study with instrumented elephant seals in the Kerguelen region (Southern Ocean), Limnol. Oceanogr. Methods, 10, 483-495, doi:10.4319/lom.2012.10.483, 2012. 